\title{
THE EFFECTIVINESS OF CHEMICAL PRACTICUM KIT TO TRAIN SCIENCE PROCESS SKILL IN $10^{\mathrm{TH}}$ GRADE
}

\author{
Rani Kurnia Ningsih ${ }^{1}$, Rusly Hidayah ${ }^{2 *}$ \\ ${ }^{1,2}$ Jurusan Kimia, FMIPA, Universitas Negeri Surabaya \\ *Corresponding author: ruslyhidayah@unesa.ac.id
}

\begin{abstract}
The purpose of this study was to obtain a chemical practicum KIT as an effective learning media to train students's science process skills on scientific method, polar and nonpolar covalent compounds, electrolyte and non-electrolyte solutions. This study uses a 4-D research model which includes the stages of defining, designing, developing, and distributing. However, in this study only limited to the development stage. The results of the research obtained showed that classical completeness in the posttest workmanship on all three materials was $100 \%$. While the increase in learning outcomes aspects of science process knowledge and skills in the three materials are in the category of "medium" and "high". Based on the results, it can be concluded that the practicum KIT learning media is effective for training science process skillson scientific method, polar and non-polar covalent compounds, and electrolyte and non-electrolyte solutions.
\end{abstract}

Keywords: practicum KIT,science process skills, effectiviness

\section{PENDAHULUAN}

Seperti yangtertera dalam Permendikbud No. 21 Tahun 2016 tentang Standar Isi Pendidikan Dasar dan Menengah, yang menjelaskan bahwa kompetensi yang harus dicapai oleh siswa dalam kompetensi inti pengetahuan adalah memahami pengetahuan faktual, konseptual, prosedural, dan metakognitif pada tingkat dasar dengan cara mengamati, menanya, dan mencoba. Dalam kurikulum 2013 revisi terdapat sebuah amanah mengenai esensi pendekatan ilmiah dalam pembelajaran yang dipandang sebagai titian dalam perkembangan dan pengembangan sikap, keterampilan, dan pengetahuan siswa. Sehingga dalam pelaksanaannya, pendekatan ilmiah akan dapat diajarkan dengan baik dalam proses belajar mengajar. Pendekatan ilmiah erat kaitannya dengan metode ilmiah. Metode ilmiah sendiri mengarah pada investigasi fenomena, mendapatkan pengetahuan baru, atau mencocokkan dan menggabungkan pengetahuan sebelumnya [1].

Kimia merupakan salah satu mata pelajaran dalam kurikulum 2013.Ilmu kimia merupakan salah satu bagian dari ilmu pengetahuan alam yang khusus mempelajari susunan, sifat-sifat, dan perubahan materi [2]. Dalam pelaksanaannya, ilmu kimia perlu pembuktian eksperimen untuk memperoleh fakta, konsep, teori, dan prinsip. Sehingga dalam mengajarkan ilmu kimia, seorang guru kimia tidak boleh hanya mengajarkan ilmu kimia secara teoritis saja, melainkan harus disertakan kegiatan praktikum untuk membantu siswa memahami materi ilmu kimia yang diajarkan [3].

Dalam belajar ilmu kimia, setidaknya dapat tercapai tiga komponen yang diinginkan, yaitu proses ilmiah, sikap ilmiah, dan produk ilmiah. Komponen proses ilmiah digunakan dalam melakukan proses penyelidikan ilmiah. Sikap ilmiah yang perlu ditumbuhkan yaitu: tanggungjawab, keingintahuan, jujur, terbuka, objektif, toleransi, kerja keras, kecermatan bekerja, disiplin, percaya diri, konsep diri positif, terbuka, peka terhadap fenomena, dan mampu menafsirkan gejala alam dari sudut prinsip-prinsip ilmiah. Dengan melakukan proses ilmiah yang didasari sikap ilmiah, maka siswa dapat mendapatkan penemuanpenemuan fakta, konsep atau teori yang semuanya disebut sebagai produk ilmiah [4].

Vol. 3, No. 1, June 2019 (1-8) 
Namun, pada kenyataannya, pengajaran ilmu kimia di SMA ternyata masih belum relevan dengan tujuan yang diharapkan dalam kurikulum 2013 revisi yakni mendorong siswa secara aktif untuk memahami konsep-konsep kimia tanpa mengabaikan hakikat ilmu kimia sebagai produk dan proses ilmiah. Pengajaran ilmu kimia selama ini hanya menekankan ilmu kimia sebagai produk sehingga keterampilan proses dan psikomotor siswa sering terabaikan [5]. Berdasarkan pemaparan tersebut, maka dalam penelitian ini akan difokuskan tentang komponen ilmu kimia sebagai proses ilmiah.

Salah satu cara yang dapat dilakukan untuk mengajarkan ilmu kimia sebagai proses kepada siswa adalah dengan melatihkan keterampilan proses sains (KPS) kepada siswa. KPS merupakan suatu pendekatan yang dalam pengaplikasiannya menuntut siswa agar bisa menerapkan metode-metode ilmiah selama kegiatan pembelajaran berlangsung [1]. Pembelajaran dengan melatihkan KPS telah dirancang sedemikian rupa sehingga siswa bisa menemukan fakta serta membangun konsep dan teori sehingga dapat mengembangkan keterampilan intelektual atau kemampuan berpikir siswa [5]. Oleh karena itu, dengan menggunakan KPS sebagai pendekatan dalam penyampaian pembelajaran, tentunya akan melatihkan keterampilanketerampilan kepada siswa, sehingga siswa tidak hanya unggul dalam aspek kognitif saja, namun juga unggul dalam aspek psikomotor dan afektif.

Berdasarkan hasil pra penelitian yang telah dilakukan di SMA Negeri 1 PorongSidoarjo diperoleh hasil bahwa sebanyak 50\% dari 34 siswa tidak senang dengan pelajaran kimia karena materi pelajarannya sulit, terlalu banyak menghafal, dan kurang bisa divisualisasikan. Pembelajaran kimia yang dilakukan selama ini hanya sebatas pembelajaran di kelas dan jarang melakukan kegiatan praktikum. Kegiatan praktikum yang dilakukan selama kelas $\mathrm{X}$ hanya satu praktikum, yaitu uji larutan elektrolit dan non elektrolit saja. Padahal sebanyak 94\% dari 34 siswa menyatakan bahwa lebih senang jika dilaksanakan pembelajaran dengan kegiatan praktikum dan akan lebih mudah dalam membantu memahami materi kimia. Selain itu, hanya ada sebanyak $20 \%$ dari 34 siswa yang mendapatkan nilai kimia diatas 75 . Melalui hasil pra penelitian ini didapatkan juga data bahwa kemampuan KPS siswa masih rendah, yakni hanya $50 \%$ siswa yang mampu membuat hipotesis dengan baik; sebanyak $61,76 \%$ siswa dapat mengamati dan menuliskan hasil pengamatan kedalam tabel pengamatan dengan baik; sebanyak $8,82 \%$ siswa yang dapat menganalisis data denganbaik; dan sebanyak $55,88 \%$ siswa yang dapat mengklasifikasikan dan membuat kesimpulan dengan baik. Sehingga, menurut data yang telah diperoleh tersebut dapat ditarik kesimpulan bahwa keterampilan proses sains perlu untuk dilatihkan.

Untuk menunjang keterlaksanaan kegiatan eksperimen dalam pembelajaran kimia, tentunya diperlukan laboratorium sehingga kegiatan praktikum dapat berlangsung.Namun, pada kenyataannya tidak semua sekolah memiliki laboratorium sehingga diperlukan suatu media pembelajaran yang dapat memfasilitasi berlangsungnya kegiatan praktikum di sekolah.Media pembelajaran yang dianggap tepat untuk mengatasi masalah keterbatasan dalam melakukan kegiatan praktikum kimia adalah KIT praktikum kimia. KIT (Komponen Instrumen Terpadu) merupakan istilah untuk alat peraga atau alat yang digunakan untuk percobaan dalam pembelajaran. KIT praktikum terdiri dari sebuah kotak yang berisi seperangkat alat dan bahan untuk kegiatan praktikum yang dikemas secara praktis. Keunggulan dalam menggunakan KIT praktikum sebagai media pembelajaran antara lain dapat menjadikan kegiatan praktikum lebih mudah dan praktis, mengurangi limbah praktikum karena praktikum dilakukan dalam skala kecil, lebih aman, dan dapat mengurangi resiko kecelakaan di laboratorium [6].

Dalam penelitian ini, KIT praktikum yang dikembangkan akan dilengkapi dengan Lembar Kerja Siswa (LKS) dan kunci jawaban LKS serta buku panduan KIT praktikum yang berisi tentang penjelasan penggunaan KIT praktikum, spesifikasi alat dan bahan beserta Material Safety Data Sheet (MSDS), cara perawatan KIT, serta rancangan percobaan judul praktikum yang akan dilakukan yaitu identifikasi pewarna alami dan buatan pada tahu kuning untuk materi metode ilmiah, identifikasi sifat kepolaran senyawa berdasarkan pengaruh medan listrik statis,

Vol. 3, No. 1, June 2019 (1-8) 
serta uji larutan elektrolit dan non elektrolit berdasarkan daya hantar listriknya.

Penelitian pengembangan KIT praktikum kimia pernah dilakukan oleh Rusdianawati \& Sukarmin yang menyatakan bahwa media KIT praktikum untuk melatihkan keterampilan proses sains pada materi kesetimbangan kimia telah dinyatakan layak sebagai media pembelajaran dengan rincian memperoleh validitas dengan persentase rata-rata sebesar $77,07 \%$ yang berada pada kategori valid, memperoleh nilai kepraktisan dengan jumlah 97,92\% siswa memberikan respon positif terhadap pembelajaran menggunakan KIT praktikum, ketuntasan klasikal mencapai $100 \%$ dan peningkatan hasil belajar termasuk dalam kategori "sedang" dan "tinggi" yang menyatakan media KIT tersebut efektif [7].

Sehingga, berdasarkan permasalahan yang telah diuraikan, maka di usulkan suatu gagasan tentang pengembangan media untuk menunjang kegiatan praktikum di sekolah dan untuk melatihkan KPS siswa. Sehingga dipandang perlu untuk melaksanakan penelitian yang berjudul "Keefektifan KIT Praktikum Kimia sebagai Media Pembelajaran untuk Melatihkan Keterampilan Proses Sains Siswa SMA Kelas X pada Materi Metode Ilmiah, Senyawa Kovalen Polar dan Non Polar, serta Larutan Elektrolit dan Non Elektrolit."

\section{METODE}

Penelitian ini merupakan jenis penelitian pengembangan KIT (Komponen Instrumen Terpadu) untuk melatihkan KPS siswa SMA kelas $\mathrm{X}$ pada materi metode ilmiah, senyawa kovalen polar dan non polar, serta larutan elektrolit dan non elektrolit. Model penelitian yang digunakan adalah model 4P (Pendefinisian, Perancangan, Pengembangan, dan Penyebaran) yang telah termodifikasi dari model 4D (Define, Design, Develop, and Disseminate) dari Thiagarajan [8].Namun, pada penelitian ini hanya dibatasi sampai pada tahap pengembangan.

Pelaksanaan uji coba terbatas dilakukan terhadap 12 orang siswa kelas XI MIPA 3 di SMA Negeri 1 Porong Sidoarjo dengan menggunakan One Group Pretest Posttest Design [9].
Keterangan:

$$
\begin{aligned}
\mathrm{O}_{1}= & \begin{array}{l}
\text { pretest (tes aspek pengetahuan } \\
\text { dan keterampilan proses sains }
\end{array} \\
& \text { sebelum diberi perlakuan } \\
& \text { penggunaan KIT praktikum } \\
& \text { yang dikembangkan) } \\
\mathrm{X}= & \text { perlakuan (KIT praktikum untuk } \\
& \text { melatihkan keterampilan proses } \\
& \text { sains siswa) } \\
\mathrm{O}_{2}= & \text { posttest (tes aspek pengetahuan } \\
& \text { dan keterampilan proses sains } \\
& \begin{array}{l}
\text { setelah diberi perlakuan } \\
\text { penggunaan KIT praktikum }
\end{array} \\
& \text { yang dikembangkan) }
\end{aligned}
$$

Pelaksanaan uji coba di kelas XI dikarenakan dalam penelitian pengembangan, harus dipilih siswa yang sudah menerima materi yang akan diujikan. Instrumen yang digunakan dalam penelitian ini adalah lembar pretest dan posttest.

Data hasil belajar siswa dianalisis secara kuantitatif dengan rumus sebagai berikut.

Nilai $=\frac{\text { skor yang diperoleh }}{\text { skor maksimal }} \times 100$

Kemudian, untuk menganalisis skor KPS siswa digunakan rumus sebagai berikut.

Penilaian KPS $=\frac{\text { skor } \text { yang diperoleh }}{\text { skor } \text { maksimal }} \times 100$

Keefektifan dari media KIT praktikum kimia yang dikembangkan akan ditinjau dari ketuntasan klasikal dan peningkatan hasil belajar siswa. Dalam hal ini, peningkatan hasil belajar yang dimaksud adalah hasil belajar aspek pengetahuan dan hasil belajar keterampilan proses sains yang dapat dilihat dari peningkatan nilai yang diperoleh siswa pada saat melakukan pretetst dan posttest. Kegiatan pretest dan posttest dilakukan pada materi metode ilmiah, senyawa kovalen polar dan non polar, serta larutan elektrolit dan non elektrolit.Selanjutnya, nilai pretest dan posttest digunakan untuk mengetahui kategori gain (peningkatan) siswa menggunakan rumus normal gain sebagai berikut [10].

$$
<g>=\frac{\%<G>}{\%<G>\max }=\frac{\%(<S f>-\%<S i>)}{(100-\%<S i>)}
$$


Keterangan:

$\mathrm{Sf}=$ nilai posttest

$\mathrm{Si}=$ nilai pretest

Sebelum hasil nilai pretest dan posttest dihitung dengan $n$-gain, data nilai siswa diuji normalitas terlebih dahulu untuk menentukan data yang diperoleh telah berdistribusi normal.Uji normalitas dilakukan menggunakan SPSS versi 16.0 dengan uji KolmogorovSmirnov yang menunjukkan bahwa data yang diperoleh berdistribusi normal dengan $\alpha=$ 0,05 . Setelah diuji normalitas dan dinyatakan berdistribusi normal, maka nilai gain dapat dihitung.Selanjutnya, angka yang didapatkan dikonversikan dengan kategori sebagai berikut.

\section{Tabel 1. Kategori Gain}

\begin{tabular}{cc}
\hline Skor Rata-rata $(\%)$ & Kategori \\
\hline $\mathrm{g}<0,3$ & Rendah \\
$0,3 \leq \mathrm{g}<0,7$ & Sedang \\
$\mathrm{g} \geq 0,7$ & Tinggi
\end{tabular}

\section{HASIL DAN PEMBAHASAN}

Tujuan mengetahui keefektifansuatu media pembelajaran KIT praktikum adalahuntuk mengetahui apakah KIT praktikum yang dikembangkan telah efektif jika ditinjau dari ketuntasan klasikal dan peningkatan hasil belajar.Desain KIT praktikum yang dikembangkan terdiri dari kotak KIT praktikum, LKS dan kunci jawaban LKS, serta buku panduan KIT praktikum.Berikut ini merupakan desain kotak KIT praktikum yang dikembangkan.
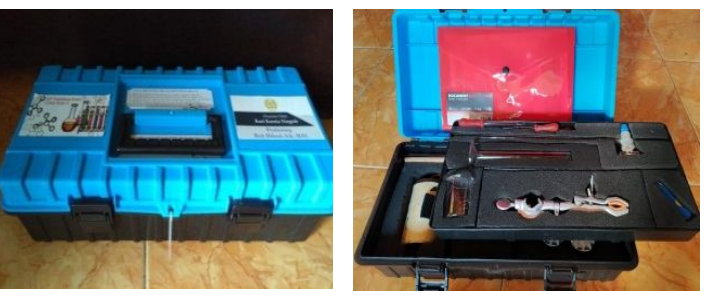

Vol. 3, No. 1, Jun€ 
Gambar 2. Tampilan desain sampul depan pada (a) LKS materi metode ilmiah, (b) LKS materi senyawa kovalen polar dan non polar, (c) LKS materi larutan elektrolit dan non elektrolit, (d) buku panduan KIT praktikum.

Untuk menentukan keefektifan dari KIT praktikum sebagai media pembelajaran, maka perlu dilakukan pretest dan posttest terhadap 12 siswa yang menjadi uji coba terbatas. Soal pretest dan posttest meliputi soal terkait keterampilan proses sains dan soal aspek pengetahuan pada materi metode ilmiah, senyawa kovalen polar dan non polar, serta larutan elektrolit dan non elektrolit. Hasil pretest dan posttest selanjutnya digunakan untuk menentukan ketuntasan klasikal dan peningkatan hasil belajar siswa.Seorang siswa dikatakan tuntas secara individu apabila nilai yang didapatkan melebihi batas KKM yang ditentukan oleh sekolah. Oleh karena dalam hal ini KKM yang diterapkan di SMA Negeri 1 Porong Sidoarjo adalah 75, maka siswa yang mendapatan nilai diatas 75 dianggap telah tuntas secara individu. Berdasarkan panduan penilaian oleh pendidik dan satuan pendidikan dalam Departemen Pendidikan dan Kebudayaan Tahun 2017 menyatakan bahwa dalam suatu pembelajaran, ketuntasan klasikal minimal harus mencapai 85\% [12]. Sedangkan untuk peningkatan hasil belajar harus berada pada kategori "sedang" dan "tinggi" agar suatu media bisa dikatakan efektif [10]. Hasil belajar aspek pengetahuan pada materi metode ilmiah adalah sebagai berikut.

Tabel 2. Hasil Belajar Aspek Pengetahuan Siswa padaMateri Metode Ilmiah

\begin{tabular}{ccccc}
\hline $\begin{array}{c}\text { Siswa } \\
\text { ke- }\end{array}$ & $\begin{array}{c}\text { Nilai } \\
\text { pretest }\end{array}$ & $\begin{array}{c}\text { Nilai } \\
\text { Posttest }\end{array}$ & $\begin{array}{c}n- \\
\text { gain }\end{array}$ & Kriteria \\
\hline 1 & 60 & 80 & 0,5 & Sedang
\end{tabular}

\begin{tabular}{ccccc}
2 & 70 & 90 & 0,67 & Sedang \\
3 & 70 & 80 & 0,33 & Sedang \\
4 & 70 & 90 & 0,67 & Sedang \\
5 & 60 & 90 & 0,75 & Tinggi \\
6 & 40 & 80 & 0,67 & Sedang \\
7 & 80 & 100 & 1 & Tinggi \\
8 & 40 & 80 & 0,67 & Sedang \\
9 & 80 & 100 & 1 & Tinggi \\
10 & 40 & 80 & 0,67 & Sedang \\
11 & 70 & 90 & 0,67 & Sedang \\
12 & 60 & 90 & 0,75 & Tinggi \\
\hline
\end{tabular}

Hasil belajar aspek pengetahuan siswa pada materi senyawa kovalen polar dan non polar dapat dilihat pada Tabel 3.

Tabel 3. Hasil Belajar Aspek Pengetahuan Siswa pada Materi Senyawa Kovalen Polar dan Non Polar

\begin{tabular}{|c|c|c|c|c|}
\hline $\begin{array}{c}\text { Siswa } \\
\text { ke- }\end{array}$ & $\begin{array}{c}\text { Nilai } \\
\text { pretest }\end{array}$ & $\begin{array}{c}\text { Nilai } \\
\text { Posttest }\end{array}$ & $\begin{array}{c}n- \\
\text { gain }\end{array}$ & Kriteria \\
\hline 1 & 40 & 80 & 0,67 & Sedang \\
\hline 2 & 50 & 80 & 0,6 & Sedang \\
\hline 3 & 60 & 90 & 0,75 & Tinggi \\
\hline 4 & 50 & 80 & 0,6 & Sedang \\
\hline 5 & 60 & 80 & 0,5 & Sedang \\
\hline 6 & 50 & 80 & 0,6 & Sedang \\
\hline 7 & 60 & 90 & 0,75 & Tinggi \\
\hline 8 & 60 & 90 & 0,75 & Tinggi \\
\hline 9 & 70 & 90 & 0,67 & Sedang \\
\hline 10 & 40 & 80 & 0,67 & Sedang \\
\hline 11 & 50 & 80 & 0,6 & Sedang \\
\hline 12 & 60 & 90 & 0,75 & Tinggi \\
\hline enge & kan & $\begin{array}{l}\text { hasil } \\
\text { pada }\end{array}$ & $\begin{array}{r}\text { belaja } \\
\text { mate }\end{array}$ & $\begin{array}{r}\text { aspek } \\
\text { larutan }\end{array}$ \\
\hline
\end{tabular}

Vol. 3, No. 1, June 2019 (1-8) 
elektrolit dan non elektrolit dapat dilihat pada Tabel 4.

Tabel 4. Hasil Belajar Aspek Pengetahuan Siswa Pada Materi Larutan Elektrolit dan Non Elektrolit

\begin{tabular}{ccccc}
\hline $\begin{array}{c}\text { Siswa } \\
\text { ke- }\end{array}$ & $\begin{array}{c}\text { Nilai } \\
\text { pretest }\end{array}$ & $\begin{array}{c}\text { Nilai } \\
\text { Posttest }\end{array}$ & $\begin{array}{c}n- \\
\text { gain }\end{array}$ & Kriteria \\
\hline 1 & 60 & 90 & 0,75 & Tinggi \\
2 & 60 & 80 & 0,5 & Sedang \\
3 & 80 & 100 & 1 & Tinggi \\
4 & 70 & 90 & 0,67 & Sedang \\
5 & 50 & 80 & 0,6 & Sedang \\
6 & 50 & 80 & 0,6 & Sedang \\
7 & 70 & 90 & 0,67 & Sedang \\
8 & 60 & 90 & 0,75 & Tinggi \\
9 & 80 & 100 & 1 & Tinggi \\
10 & 50 & 80 & 0,6 & Sedang \\
11 & 70 & 90 & 0,67 & Sedang \\
12 & 70 & 100 & 1 & Tinggi \\
\hline
\end{tabular}

Berdasarkan pada Tabel 2, Tabel 3, dan Tabel 4 didapatkan data bahwa pada hasil belajar aspek pengetahuan, didapatkan hasil pada kegiatan posttest untuk materi metode ilmiah, senyawa kovalen polar dan non polar, serta larutan elektrolit dan non elektrolit dari kedua belas siswa telah mendapat nilai diatas 75 yang menandakan bahwa untuk aspek pengetahuan pada ketiga materi tersebut telah tuntas secara klasikal dengan persentase sebesar $100 \%$.

Sedangkan untuk peningkatan hasil belajar didapatkan data bahwa terdapat 4 siswa memperoleh $n$-gain dengan kategori tinggi sedangkan 8 siswa lainnya memperoleh kategori sedang pada materi metode ilmiah.Untuk materi senyawa kovalen polar dan non polar, terdapat 4 siswa mendapatkan $n$-gain dengan kategori tinggi dan 8 siswa lainnya mendapatkan $n$-gain dengan kategori sedang.Kemudian untuk materi larutan elektrolit dan non elektrolit, terdapat 5 siswa memperoleh $n$-gain dengan kategori tinggi dan 7 siswa lainnya memperoleh $n$-gain dengan kategori sedang.

Selain ditinjau dari hasil belajar aspek pengetahuan, keefektifan media KIT praktikum juga ditinjau dari hasil belajar KPS yang meliputi soal tentang merumuskan hipotesis, mengamati, menginterpretasi data, mengklasifikasikan, dan menyimpulkan.Hasil belajar KPS ini menunjukkan apakah KPS sudah berhasil dilatihkan dengan baik kepada siswa atau masih belum, karena mengingat media pembelajaran KIT praktikum yang dibuat bertujuan untuk melatihkan KPS siswa pada materi metode ilmiah, senyawa kovalen polar dan non polar, serta larutan elektrolit dan non elektrolit.Hasil belajar KPS pada materi metode ilmiah adalah sebagai berikut.

Tabel 5. Hasil Belajar KPS pada Materi Metode Ilmiah

\begin{tabular}{ccccc}
\hline $\begin{array}{c}\text { Siswa } \\
\text { ke- }\end{array}$ & $\begin{array}{c}\text { Nilai } \\
\text { pretest }\end{array}$ & $\begin{array}{c}\text { Nilai } \\
\text { Posttest }\end{array}$ & $\begin{array}{c}n- \\
\text { gain }\end{array}$ & Kriteria \\
\hline 1 & 63 & 92 & 0,78 & Tinggi \\
2 & 70 & 96 & 0,86 & Tinggi \\
3 & 44 & 88 & 0,78 & Tinggi \\
4 & 70 & 96 & 0,86 & Tinggi \\
5 & 41 & 79 & 0,64 & Sedang \\
6 & 44 & 88 & 0,78 & Tinggi \\
7 & 63 & 96 & 0,89 & Tinggi \\
8 & 41 & 88 & 0,79 & Tinggi \\
9 & 48 & 88 & 0,76 & Tinggi \\
10 & 33 & 79 & 0,68 & Sedang \\
11 & 44 & 96 & 0,92 & Tinggi \\
12 & 48 & 96 & 0,92 & Tinggi
\end{tabular}

Hasil belajar KPS pada materi senyawa kovalen polar dan non polar dapat dilihat pada Tabel 6.

Tabel 6. Hasil Belajar KPS pada Materi Senyawa Kovalen Polar dan Non Polar

Vol. 3, No. 1, June 2019 (1-8) 


\begin{tabular}{ccccc}
\hline $\begin{array}{c}\text { Siswa } \\
\text { ke- }\end{array}$ & $\begin{array}{c}\text { Nilai } \\
\text { pretest }\end{array}$ & $\begin{array}{c}\text { Nilai } \\
\text { Posttest }\end{array}$ & $\begin{array}{c}n- \\
\text { gain }\end{array}$ & Kriteria \\
\hline 1 & 30 & 81 & 0,73 & Tinggi \\
2 & 40 & 89 & 0,81 & Tinggi \\
3 & 26 & 85 & 0,79 & Tinggi \\
4 & 48 & 93 & 0,86 & Tinggi \\
5 & 37 & 78 & 0,65 & Sedang \\
6 & 26 & 78 & 0,70 & Tinggi \\
7 & 26 & 80 & 0,73 & Tinggi \\
8 & 40 & 93 & 0,88 & Tinggi \\
9 & 30 & 78 & 0,68 & Sedang \\
10 & 37 & 89 & 0,82 & Tinggi \\
11 & 26 & 85 & 0,79 & Tinggi \\
12 & 30 & 81 & 0,73 & Tinggi \\
\hline
\end{tabular}

Sedangkan hasil belajar KPS pada materi larutan elektrolit dan non elektrolit dapat dilihat pada Tabel 7.

Tabel 7. Hasil Belajar KPS pada Materi Larutan Elektrolit dan Non Elektrolit

\begin{tabular}{ccccc}
\hline $\begin{array}{c}\text { Siswa } \\
\text { ke- }\end{array}$ & $\begin{array}{c}\text { Nilai } \\
\text { pretest }\end{array}$ & $\begin{array}{c}\text { Nilai } \\
\text { Posttest }\end{array}$ & $\begin{array}{c}\boldsymbol{n} \text { - } \\
\text { gain }\end{array}$ & Kriteria \\
\hline 1 & 48 & 85 & 0,71 & Tinggi \\
2 & 48 & 92 & 0,84 & Tinggi \\
3 & 37 & 89 & 0,82 & Tinggi \\
4 & 52 & 96 & 0,91 & Tinggi \\
5 & 37 & 89 & 0,82 & Tinggi \\
6 & 37 & 89 & 0,82 & Tinggi \\
7 & 48 & 92 & 0,84 & Tinggi \\
8 & 50 & 96 & 0,92 & Tinggi \\
9 & 48 & 85 & 0,71 & Tinggi \\
10 & 37 & 85 & 0,76 & Tinggi \\
\hline
\end{tabular}

\begin{tabular}{ccccc}
\hline $\begin{array}{c}\text { Siswa } \\
\text { ke- }\end{array}$ & $\begin{array}{c}\text { Nilai } \\
\text { pretest }\end{array}$ & $\begin{array}{c}\text { Nilai } \\
\text { Posttest }\end{array}$ & $\begin{array}{c}\text { n- } \\
\text { gain }\end{array}$ & Kriteria \\
\hline 11 & 48 & 85 & 0,71 & Tinggi \\
12 & 50 & 89 & 0,78 & Tinggi \\
\hline
\end{tabular}

Berdasarkan data pada Tabel 5, Tabel 6, dan Tabel 7, didapatkan data bahwa pada hasil belajar KPS didapatkan hasil pada kegiatan posttest untuk materi metode ilmiah, senyawa kovalen polar dan non polar, serta larutan elektrolit dan non elektrolit dari kedua belas siswa telah mendapat nilai diatas 75 yang menandakan bahwa untuk aspek KPS pada ketiga materi tersebut telah tuntas secara klasikal dengan persentase sebesar $100 \%$.

Peningkatan hasil belajar aspek KPS untuk materi metode ilmiah yaitu terdapat 10 siswa yang memiliki $n$-gain dengan kategori tinggi, sedangkan 2 siswa lainnya memperoleh kategori sedang.Pada materi senyawa kovalen polar dan non polar ada sebanyak 10 siswa mendapatkan nilai $n$-gain dengan kategori tinggi, sedangkan 2 siswa lainnya mendapatkan kategori sedang.Pada materi larutan elektrolit dan non elektrolit seluruh siswa memperoleh $n$-gain dengan kategori tinggi.

Suatu media pembalajaran dapat dikatan layak dari segi keefektifan apabila hasil belajar siswa telah tuntas secara klasikal minimal $85 \%$ [12] dan mengalami peningkatan hasil belajar dengan kategori "sedang" dan "tinggi" [10]. Oleh karena pada penelitian inihasil belajar siswa telah mengalami ketuntasan secara klasikal dengan persentase sebesar $100 \%$ baik hasil belajar aspek pengetahuan dan KPS serta data hasil pretest dan posttes siswa mengalami peningkatan yang berada pada kategori sedang dan tinggi baik itu hasil belajar aspek pengetahuan maupun hasil belajar KPS, maka dapat disimpulkan bahwa media KIT praktikum kimia untuk melatihkan keterampilan proses sains siswa kelas $\mathrm{X}$ pada materi metode ilmiah, senyawa kovalen polar dan non polar, serta larutan eleketrolit dan non elektrolit telah efektif dan layak untuk digunakan dalam kegiatan pembelajaran kimia.

SIMPULAN DAN SARAN Simpulan

Vol. 3, No. 1, June 2019 (1-8) 
Berdasarkan hasil penelitian yang telah dilakukan, maka dapat disimpulkan bahwa media KIT praktikum kimia sebagai media pembelajaran untuk melatihkan KPS siswa SMA kelas $\mathrm{X}$ pada materi metode ilmiah, senyawa kovalen polar dan non polar, serta larutan elektrolit dan non elektrolit dapat dinyatakan efektif yang ditinjau dari ketuntasan klasikal sebesar $100 \%$ pada ketiga materi tersebut dan peningkatan hasil belajar siswa yang memperoleh kategori "sedang" dan "tinggi" pada ketiga materi tersebut.

\section{Saran}

Berdasarkan hasil kesimpulan diatas, saran yang dapat diajukan untuk penelitian selanjutntnya adalah perlu dilatihkannya KPS untuk materi yang lainnya dalam pembelajaran kimia, karena dengan melatihkan KPS terbukti efektif dalam meningkatkan pemahaman dan hasil belajar siswa terhadap materi yang diajarkan.

\section{DAFTAR PUSTAKA}

1. Yamtinah, S., Sulistyo S., Haryono, Budi U. \& Rahmah R. A. W. 2016. Keterampilan Proses Sains (KPS) siswa SMA Kelas XI pada Materi Hidrolisis Garam. [Prosidding]. Seminar Nasional Kimia dan Pendidikan Kimia VIII. Universitas Sebelas Maret.

2. Watoni, A. H., Kurniawati, D., Juniastri, M. 2016. Kimia untuk Siswa SMA Kelas $X$ Peminatan. Bandung: Yrama Widya.

3. Zidny, R., Dirayati Y., Intan A. \& Nur I. E. 2017. Uji Kelayakan KIT Praktikum Pengujian Kepolaran Senyawa dari Material Sederhana. Jurnal Riset Pendiidkan Kimia, 7(1): 52-58.

4. Azizah, U., Mitarlis, Nuniek, H., Sari, E. C., Siti T., Bertha Y., \& Amaria. 2017. Kimia Dasar I. Surabaya: UNESA University Press.
5. Buanarinda, T. P. \& Rusly, H. 2014. Meningkatkan Keterampilan Proses Sains Melalui Model Pembelajaran Guided Inquiry pada Pembelajaran Konsep Asam Basa Kelas XI SMA Negeri Ploso Jombang. UNESA Journal of Chemical Education. 3 (3): 8-12.

6. Akmalia, N., Silaban, R., \& Mahmud. 2018. The Influence of Innovation Chemistry Practicum Guide and KIT Integrated Guided Inquiry Model for on Students Skills for Class XI Second Semester Senior High School. Advances in Social Science, Education and Humanities Research. 200 (3): 61-66.

7. Rusdianawati, D. \& Sukarmin. 2017. Pengemabangan KIT Praktikum sebagai Media Pembelajaran untuk Melatihkan Keterampilan Proses Sains Berbasis Inkuiri pada Materi kesetimbangan Kimia Kelas XI. UNESA Journal of Chemistry Education. 6 (2): 308-314.

8. Ibrahim, M. \& Wahyusukartiningsih. 2014. Model Pembelajaran Inovatif Melalui Pemaknaan. Surabaya: UNESA University Press.

9. Sugiyono. 2015. Metode Penelitian Pendidikan: Pendekatan Kuantitatif, Kualitatif, dan $R \& D$. Bandung: Alfabeta.

10. Hake, R. R. 1998. Interactive-engagement Versus Traditional Methods: A SixThousand-Student Survey of Mechanics Test Data for Introductory Physics Course. American Journal of Physics. 66 (64): 64-74.

11. Kheng, Y. T. 2008. Science Process Skills From 3. Selangor Darul Ehsan: Pearson Malaysia Sdn. Bhd.

12. Departemen Pendidikan dan Kebudayaan. 2017. Panduan Penilaiana oleh Pendidik dan Satuan Pendidikan. 